Original article

\title{
The perception of parental bonding in pregnant adolescents and its association with generalized anxiety disorder
}

\author{
Mariana Bonati de Matos*, Carolina Coelho Scholl, Jéssica Puchalski Trettim, \\ Mariane Lopez Molina, Mariana Carret Soares, Fernanda Teixeira Coelho, \\ Rochele Dias Castelli, Ricardo Azevedo da Silva, Karen Amaral Tavares Pinheiro, \\ Fábio Monteiro da Cunha Coelho, Luciana de Avila Quevedo, Ricardo Tavares Pinheiro
}

Postgraduate Programme in Health and Behavior, Catholic University of Pelotas (UCPel) - Gonçalves Chaves, 377 - 411 C - CEP: $96015-560$ Pelotas, RS Brazil

A R T I C L E I N F O

Article history:

Received 24 April 2018

Received in revised form 30 July 2018

Accepted 31 July 2018

Available online 24 August 2018

\section{Keywords:}

Lack of care

Overprotection

Maternal

Pregnant adolescents

GAD

Anxiety

\begin{abstract}
A B S T R A C T
Background: The parental bonding is influenced by two dimensions: care and control or protection over the child of both parents. The lack of care during childhood may make the individual more susceptible to the onset of psychiatric disorders when adult. These psychiatric disorders when present during pregnancy may have a negative impact on the health of pregnant women and children. The aim of this study was to assess the association between generalized anxiety disorder (GAD) in pregnant adolescents and the perception of parental bonding.

Methods: This is a cross-sectional study with 871 pregnant women under the age of 19, receiving prenatal care in 47 Basic Health Units in the one city, Brazil. The generalized anxiety disorder was measured using the Mini International Neuropsychiatric Interview (MINI) and the perception of parental bonding in childhood using the Parental Bonding Instrument (PBI).

Results: The prevalence of GAD was 8.5\%. Among all the parental bonding dimensions, only a perceived lack of maternal care under 16 years was associated with GAD.

Conclusions: The results showed that only the perception of maternal bonding was associated with later GAD. It suggests that an adequate maternal bond is an essential component of psychological health.
\end{abstract}

(c) 2018 Elsevier Masson SAS. All rights reserved.

\section{Introduction}

Adolescents have an elevated risk for medical complications in pregnancy compared to adult women [1]. The rate of neonatal death for adolescent pregnancies, which includes stillbirth as well as infant death up to 28 days old, is roughly 3 times higher than adult pregnancies [2]. Moreover, teenage pregnancy also seems to heighten the risk of psychiatric disorders [3-5]. In this sense, the primary focus of extant literature is on depression, while anxiety disorders remain somewhat neglected.

Anxiety disorders during pregnancy are relatively common, with reported prevalence rates about 15\%, and frequently associated with negative outcomes [6]. Specially, generalized anxiety disorder (GAD) is one of the most prevalent anxiety

\footnotetext{
* Corresponding author at: Post graduate Programme in Health and Behavior Catholic University of Pelotas (UCPel) Gonçalves Chaves, 377 - 411 C - 96015-560 (53) 2128-8404 Pelotas, RS, Brazil.

E-mail address: marianabonatidematos@gmail.com (M.B. de Matos).
}

disorders, only after specific phobia. The disorder is characterized by excessive and persistent anxiety and worry about daily activities. The diagnostic criteria covers physical and psychological symptoms of anxiety, causing significant impairment in social functioning [7]. Furthermore, anxious pregnant women have a higher risk to develop postnatal depressive symptoms [8] and other psychiatric disorders after birth [9]. Antenatal anxiety disorders are also associated to a higher suicide risk (mainly attributed to generalized anxiety disorder) [10] and can bring adverse consequences for the baby [11].

While Faisal-Cury, Menezes [12] reported that worry and anxiety are among the most common psychiatric symptoms during pregnancy, there are virtually no studies on GAD in pregnant adolescents. A cohort study with pregnant adults showed that $9.5 \%$ of them have suffered from this disorder at some point during pregnancy, when the highest rate of GAD was $7 \%$ in the first trimester $[13,14]$. Another study reported an $8.5 \%$ prevalence rate in the third trimester of pregnancy [15]. Environmental factors such as being single and having lower education level [16] may be important for the development of GAD in women [17]. In addition, 
women with lower social support, history of child abuse and a past history of GAD in the family have greater risk of developing GAD in pregnancy [13]. The perception of parenting styles have also been considered as relevant environmental risk factors for the development of psychiatric disorders, such as anxiety disorders [18]. The transition to motherhood can refer to past relationships of parental bonds, especially in teenagers, whose social roles are still to be defined [19]. Although one study has found GAD patients to score both of their parents as uncaring and overprotective, this relationship has not been studied in pregnant adolescents [20].

Therefore, the main goal of this study was to determine if there is an association between the perception of parental bonding and generalized anxiety disorder in pregnant adolescents. Also, we aimed to verify the factors associated with GAD.

\section{Materials and methods}

\subsection{Study type and sampling}

This is a cross-sectional study with pregnant teenagers (up to 19 years old) who were using the public services for prenatal care under the Unified National Health System in the urban area of Pelotas, a city in southern Brazil. Data were collected in 47 primary healthcare units and in 3 public obstetric clinics, starting in October 2009 and ending in March 2011. The inclusion criteria were: to be pregnant, up to 19 years old and live in the urban area of Pelotas, RS (Brazil). The exclusion criteria were: present some physical or cognitive disability that did not allow the understanding of the questionnaire.

Table 1

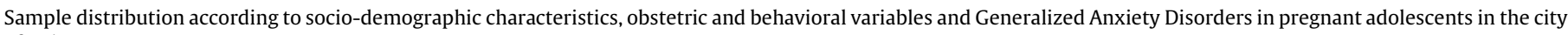
of Pelotas.

\begin{tabular}{|c|c|c|c|}
\hline Variables & $N(\%)$ & GAD (\%) & p-value \\
\hline Age $(n=870)$ & & & 0.807 \\
\hline$\leq 16$ years & $240(27.6)$ & $19(7.9)$ & \\
\hline$\geq 17$ years & $630(72.4)$ & $55(8.8)$ & \\
\hline Education $(n=869)$ & & & 0.102 \\
\hline Lessthan 5 years & $142(16.3)$ & $11(7.8)$ & \\
\hline Between 5 and 8 years & $374(43.0)$ & $41(11.0)$ & \\
\hline Between 8 and 11 years & 277 (31.9) & $20(7.3)$ & \\
\hline Between 11 and 14 years & $76(8.7)$ & $02(2.6)$ & \\
\hline Socioeconomic status $(n=851)$ & & & 0.537 \\
\hline$A+B$ & 107 (12.6) & $11(10.3)$ & \\
\hline $\mathrm{C}$ & $530(62.3)$ & $45(8.5)$ & \\
\hline $\mathrm{D}+\mathrm{E}$ & $214(25.1)$ & $17(8.0)$ & \\
\hline Works $(n=867)$ & & & 0.261 \\
\hline No & $755(87.1)$ & $61(8.1)$ & \\
\hline Yes & $112(12.9)$ & $13(11.8)$ & \\
\hline Lives with partner $(\mathrm{n}=869)$ & & & 0.804 \\
\hline No & $324(37.3)$ & $29(9.0)$ & \\
\hline Yes & $545(62.7)$ & $45(8.3)$ & \\
\hline Primiparity (n=859) & & & 0.023 \\
\hline No & $185(21.5)$ & $24(13.1)$ & \\
\hline Yes & $674(78.5)$ & $50(7.4)$ & \\
\hline Previous abortion $(n=642)$ & & & 0.001 \\
\hline No & $554(86.3)$ & $43(7.8)$ & \\
\hline Yes & $88(13.7)$ & $17(19.5)$ & \\
\hline Unplanned pregnancy $(\mathrm{n}=\mathbf{8 6 9})$ & & & 1.000 \\
\hline No & $630(72.5)$ & $53(8.5)$ & \\
\hline Yes & $239(27.5)$ & $20(8.4)$ & \\
\hline Social support $(\mathrm{n}=\mathbf{8 6 3})$ & & & 0.041 \\
\hline No & $22(2.5)$ & $05(22.7)$ & \\
\hline Yes & $841(97.5)$ & $68(8.1)$ & \\
\hline Previous or current psychiatric treatment $(n=865)$ & & & 0.061 \\
\hline No & $725(83.8)$ & $55(7.6)$ & \\
\hline Yes & $140(16.2)$ & $18(12.9)$ & \\
\hline Psychiatric family history ( $n=861$ ) & & & 0.021 \\
\hline No & $483(56.1)$ & $31(7.6)$ & \\
\hline Yes & $378(43.9)$ & $42(11.1)$ & \\
\hline Tobacco use $(n=868)$ & & & 0.932 \\
\hline No & $706(81.3)$ & $61(8.7)$ & \\
\hline Yes & $162(18.7)$ & $13(8.1)$ & \\
\hline Maternal Care $(n=802)$ & & & $<0.001$ \\
\hline No & $260(32.4)$ & $30(11.5)$ & \\
\hline Yes & $542(67.6)$ & $38(7,0)$ & \\
\hline Maternal Control ( $n=809$ ) & & & 0.787 \\
\hline Overprotection & $210(26.0)$ & $17(8.1)$ & \\
\hline Protection & $599(74.0)$ & $54(9.0)$ & \\
\hline Paternal Care $(n=707)$ & & & 0.015 \\
\hline No & $251(35.5)$ & $30(12.0)$ & \\
\hline Yes & $456(64.5)$ & $29(6.4)$ & \\
\hline Paternal Control $(n=723)$ & & & 0.520 \\
\hline Overprotection & $197(27.2)$ & $14(7.1)$ & \\
\hline Protection & $526(72.8)$ & $47(9.0)$ & \\
\hline Total & $871(100)$ & - & - \\
\hline
\end{tabular}


We calculated the sample size with the STATCALC tool of the Epi-Info software [21]. With a confidence level of $95 \%$ and power of $80 \%$, the prevalence of GAD estimated at $10 \%$ with estimated risk of 2.0, the sample size needed was 871 .

\subsection{Measures}

The GAD was assessed by the Mini International Neuropsychiatric Interview (MINI) [22]. The MINI is a short structured interview based on DSM-IV and ICD-10 criteria with adequate validity and reliability [23].

Parental bonding was assessed by the Brazilian validated version of Parental Bonding Instrument (PBI). This instrument is the most used to measure the contribution of parental behavior in the development of an adequate bond between parents and children [24]. The PBI is a self-report likert-type instrument (0-3) with 25 questions related to the subject's father and mother. The subjects answer how a particular behavior was similar to their parents' behavior until they were 16 years old. The instrument measures the following two dimensions of maternal and paternal bonds: [1] care or lack of care (affection, warmth, availability, care, sensitivity versus coldness and rejection) and [2] control or protection/overprotection (control, intrusion versus encouragement of the autonomy) (25). It brings questions like "He/She spoke to me with a warm and friendly voice" and "He/She did not help me as much as I needed" for the care dimension and questions like "He/She let me do the things I liked doing" and "He/She liked me to make my own decisions" for the control dimension. The Brazilian version of PBI presented satisfactory internal consistency for both dimensions, with Cronbach's alpha of 0.91 for care in the maternal and paternal bonding and 0.87 and 0.85 for control/protection in the maternal and paternal bonding, respectively [26].

Table 2

Crude and adjusted analysis in a sample of pregnant adolescents with Generalized Anxiety Disorder.

\begin{tabular}{|c|c|c|}
\hline Variables & $\begin{array}{l}\text { Crude Analysis } \\
\text { CI } 95 \%\end{array}$ & $\begin{array}{l}\text { Ajusted analysis } \\
\text { CI } 95 \%\end{array}$ \\
\hline \multicolumn{3}{|l|}{ Age $(n=870)$} \\
\hline$\leq 16$ years & 1.00 & \\
\hline$\geq 17$ years & $1.11(0.65 ; 1.91)$ & \\
\hline \multicolumn{3}{|l|}{ Education $(n=869)$} \\
\hline Less than 5 years & $3.13(0.67 ; 14.50)$ & $2.08(0.45 ; 9.70)$ \\
\hline Between 5 and 8 years & $4.56(1.08 ; 19.26)$ & $1.90(0.42 ; 8.68)$ \\
\hline Between 8 and 11 years & $2.90(0.66 ; 12.70)$ & $1.30(0.24 ; 7.10)$ \\
\hline Between 11 and 14 years & 1.00 & 1.00 \\
\hline \multicolumn{3}{|c|}{ Socioeconomic status $(n=851)$} \\
\hline$A+B$ & $1.31(0.59 ; 2.91)$ & \\
\hline C & $1.06(0.59 ; 1.90)$ & \\
\hline$D+E$ & 1.00 & \\
\hline \multicolumn{3}{|l|}{ Works $(n=867)$} \\
\hline No & 1.00 & \\
\hline Yes & $1.52(0.81 ; 2.87)$ & \\
\hline \multicolumn{3}{|l|}{ Lives with partner $(n=869$ ) } \\
\hline No & $1.09(0.67 ; 1.79)$ & \\
\hline Yes & 1.00 & \\
\hline \multicolumn{3}{|l|}{ Primiparity $(n=859)$} \\
\hline No & $1.88(1.12 ; 13.5)$ & $1.45(0.52 ; 4.02)$ \\
\hline Yes & 1.00 & 1.00 \\
\hline \multicolumn{3}{|l|}{ Previous abortion $(n=642)$} \\
\hline No & 1.00 & 1.00 \\
\hline Yes & $2.87(1.55 ; 5.31)$ & $3.71(1.26 ; 10.95)$ \\
\hline \multicolumn{3}{|c|}{ Unplanned pregnancy $(n=869)$} \\
\hline No & $1.01(0.59 ; 1.73)$ & \\
\hline Yes & 1.00 & \\
\hline \multicolumn{3}{|l|}{ Social support $(n=863)$} \\
\hline No & $3.33(1.19 ; 9.30)$ & $2.44(0.64 ; 9.26)$ \\
\hline Yes & 1.00 & 1.00 \\
\hline \multicolumn{3}{|c|}{ Previous or current psychiatric treatment $(n=865)$} \\
\hline No & 1.00 & 1.00 \\
\hline Yes & $1.78(1.01 ; 3.15)$ & $1.51(0.68 ; 3.34)$ \\
\hline \multicolumn{3}{|c|}{ Psychiatric family history $(n=861)$} \\
\hline No & 1.00 & 1.00 \\
\hline Yes & $1.81(1.11 ; 2.94)$ & $2.27(1.14 ; 4.53)$ \\
\hline \multicolumn{3}{|l|}{ Tobacco use $(n=868)$} \\
\hline No & $1.08(0.57 ; 2.01)$ & \\
\hline Yes & 1.00 & \\
\hline \multicolumn{3}{|l|}{ Maternal Care $(n=802)$} \\
\hline No & 1.00 & 1.00 \\
\hline Yes & $2.91(1.76 ; 4.82)$ & $2.08(1.05 ; 4.12)$ \\
\hline \multicolumn{3}{|l|}{ Maternal Control $(n=809)$} \\
\hline Overprotection & $1.12(0.64 ; 1.99)$ & \\
\hline Protection & 1.00 & \\
\hline \multicolumn{3}{|l|}{ Paternal Care $(n=707)$} \\
\hline No & $2.00(1.16 ; 3.41)$ & $1.44(0.74 ; 2.80)$ \\
\hline Yes & 1.00 & 1.00 \\
\hline \multicolumn{3}{|l|}{ Paternal Control $(n=723)$} \\
\hline Overprotection & 1.00 & \\
\hline Protection & $1.28(0.69 ; 2.39)$ & \\
\hline
\end{tabular}


We used a sociodemographic and economic questionnaire considering the following variables: age, education, socioeconomic status, works and living with a partner. The Brazilian Association of Research Companies criteria was used to assess the socioeconomic status of families [27]. This classification is based on the accumulation of material wealth and schooling of household head, classifying the subjects into five levels (A, B, C, D and E) in which the highest-income level is " $A$ " and the lowest is " $E$ ".

We collected obstetric information regarding parity, previous abortions and if the pregnancy was planned. Regarding the psychiatric history, we questioned about previous or current psychiatric treatment and if any family member have psychiatric history. Tobacco use was evaluated as the actual use.

\subsection{Statistical analysis}

For statistical analysis, we used SPSS (Statistical Package for the Social Science) program, version 13. Chi-square test was used to compare proportions. Logistic regression was employed to control for possible confounding factors.

The variables with p-value $<0.20$ [28] entered in the logistic regression analysis with a hierarchical multilevel approach, using the GAD as primary outcome. In the first level, sociodemographic and economic variables were included (age; educational years; socioeconomic status; work; lives with partner). In the second level, obstetric variables were included (primiparity; previous abortion; unplanned pregnancy). In the third level, emotional and behavioral variables (social support; previous or current psychiatric treatment; psychiatric family history; tobacco use; perception of maternal care; perception of maternal control; perception of paternal care; perception of paternal control).

\subsection{Ethical aspects}

The subjects signed a free and informed consent statement for the analysis and anonymous publication of the research findings. This project was approved by the Research Ethics Committee of the University, Brazil (protocol no. 2007/95).

\section{Results}

In this study, 870 pregnant adolescents were identified excluding $4.3 \%$ of losses and refusals. The prevalence of GAD was $8.5 \%$. Regarding PBI maternal bonding styles, the prevalence of lack of care was $32.4 \%(n=260)$ and overprotected control was $26 \%$ $(n=210)$. Regarding PBI paternal bonding styles, the prevalence rates were of $72.8 \%(n=526)$ and $27.2 \%(n=197)$, respectively.

Table 1 shows the sample's overall distribution. The raw analysis showed that GAD was associated with primiparity $(p=0.023)$, previous abortion $(p=0.001)$, perception of family support $(p=0.041)$, familial history of psychiatric disorders $(p=0.021)$, maternal lack of care $(\mathrm{p}<0.001)$ and paternal lack of care $(\mathrm{p}=0.015)$.

After adjusting for possible confounding variables, as showed in Table 2, previous abortion ( $\mathrm{p}=0.018$ ), familial history of psychiatric disorders $(p=0.019)$ and maternal lack of care $(p=0.036)$ was associated whit GAD. Pregnant women who had previous abortion were 3.71 (CI: 1.26 ; 10.95) times more likely to present GAD compared to those who had no previous abortion. For the pregnant who had familial history of psychiatric disorders, the chance of presenting GAD was 2.27 ( $\mathrm{CI}: 1.14 ; 4.53$ ) times higher than those who did not had familial history of psychiatric disorders. Pregnant teenagers who reported maternal lack of care were 2.08 (CI: 1.05; 4.12) times more likely to present GAD compared to those who reported adequate maternal care. In the adjusted analysis, the following variables were not significantly associated with GAD: education, primiparity, social support, previous or current psychiatric treatment and paternal care ( $>$ >005)."

\section{Discussion}

Parental bonding encompasses the bonding style that both parents have with their children through attitudes related to care and protection. The 'care' dimension is composed by attitudes of affection, emotional warmth, availability, care and sensitivity. Thus, parents who demonstrate coldness and rejection characterize lack of care. The 'protection' dimension, on the other hand, is composed by attitudes of surveillance and promotion of autonomy. Parents who demonstrate extreme control and intrusion characterize overprotection [26]. The literature has shown that parental bonding styles plays an important role in the developing of psychiatric symptoms in adulthood [29].

For the main purpose of this study, we expected to find an association between generalized anxiety disorder and both maternal and paternal bonding. This relationship was partially found. Only the lack of maternal care in childhood was significantly associated to GAD in pregnancy, after adjusting for potential confounders. The association between parenting style and anxiety disorders was examined in a few studies. A study conducted in six countries found an association between lack of maternal care and the presence of GAD, social phobia, specific phobia and panic disorder. They also found an association between lack of paternal care and anxiety disorders, although this dimension of parental bonding acted differently across the anxiety disorders. Yet, maternal overprotection was not associated with GAD but with the other three disorders [18]. The authors Lima, Mello [29] claim that parental dysfunction are risk factors for the development of anxiety disorders. However, we are not aware of other studies investigating this association within a population of pregnant teenagers.

According to Rubinchik, Kablinger [30] "pregnancy can bring to mind past painful events with their own parents" (p.100). It is possible that those GAD pregnant teenagers who perceived their parental bonding as unsatisfactory could be interpreting the memories regarding their parents in an anxious or pessimistic way, notwithstanding the actual childhood experience. Another possible explanation for the association of maternal bonding and GAD is that the way in which the child is raised could be considered a potential factor of vulnerability, whereas the first abstractions of the child's experience with their caregivers become mental representations of attachment relationships that reflect the way how the individual handles emotions [31]. The internalization of this perceived lack of affection in childhood can give adolescents less ability to cope with life's stressful events [25]. Although such relationship is evident, this information should be investigated more carefully, as depression can also interfere in this association [32].

Another factor associated with GAD in pregnant teenagers was the presence of a previous abortion. A meta-analysis identified that women who underwent abortion had $81 \%$ risk of mental health problems, and that nearly $10 \%$ incidence of mental health problems are directly attributed to abortion [33]. Women who have experienced an abortion in previous pregnancies can have greater fear to go through this situation again. Extreme concerns about the current pregnancy may also arise. Thus, it is necessary to have a special attention to these pregnant women. The prenatal care should integrate mental health actions to prevent or treat anxiety disorders.

As we expected, the pregnant that had familial history of psychiatric disorders had a higher chance of present GAD than those who did not had history of psychiatric disorders in family members. A review of risk factors for the onset of panic and 
generalized anxiety disorders found that a parental history of GAD [34], depression [35], or other mental health problems [36] were associated with GAD in their offspring. Furthermore, studies on psychiatric disorders in family members point out this issue as a risk factor for most psychiatric disorders. Regarding GAD, one third of the risk of presenting this disorder is of genetic origin [7]. Moreover, by witnessing the anxious and worried behavior of the parents, the child learns this behavioral pattern and begins to actually practice it, resulting in increased vulnerability to develop the disorder. The case revolves around the biological and environmental influences that interfere with the normal development of the individual, making it more susceptible to develop some mental disorder. Although the magnitude of the association between GAD and psychiatric family history is greater than the association with parental bonding, the latter one cannot be excluded, since even after adjusted analysis it remained significant.

The findings of our study should be interpreted in the light of its limitations. First, as with any cross-sectional study, causality could not be assessed. As parental bonding was measured retrospectively, we point out the risk of recall bias. Similarly, the pregnant with GAD can have assessed their parental bonding as negative as a result of their disorder and not because it was really negative [7]. A longitudinal study would be necessary to evaluate such relationship. On the other hand, previous research showed that the subject's mood did not have a significant impact on PBI, which proved stable over time [37]. Another limitation concerns the lack of a control group of non-pregnant adolescents, but the comparison was not possible due to the logistics of the study. As our sample was recruited from public health services, there is the risk of selection bias. It was also not possible to collect information about other possible confounding factors drug use and family structure.

Even with such limitations, this study has relevance, considering that in Brazil about 20\% of children were born from adolescent mothers each year, which confirms an increased need to supply this population with adequate healthcare [15]. Moreover, recent data showed that GAD has received little attention compared to other anxiety disorders, which demonstrates the importance of further studies related to the subject. Some studies suggest that environmental factors are involved in the development and maintenance of GAD, however, there is very few information in the literature.

Concluding, a perceived lack of maternal care under 19 years was associated with GAD, suggesting that the adequate maternal bond is a contributor for a psychological healthy development. The lack of care, as well as the absence of an adequate family structure during childhood may lead the individual to be more susceptible to the onset of psychiatric disorders.

Anxiety disorders in pregnancy may have a harmful impact on the health of pregnant teenagers, as it can lead to postpartum depression, low birth weight and premature birth, and, additionally, it may also have a negative impact on child development. This indicates the relevant need of early detection of these conditions, aiming to implement appropriate preventive measures $[16,30]$.

\section{Ethical approval}

All procedures performed in studies involving human participants were in accordance with the ethical standards of the institutional and/or national research committee and with the 1964 Helsinki declaration and its later amendments or comparable ethical standards. The subjects signed a free and informed consent statement for the analysis and anonymous publication of the research findings. This project was approved by the Research Ethics Committee of the Catholic University of Pelotas, Brazil (protocol no. 2007/95).

\section{Funding}

This study was funded by Conselho Nacional de DesenvolvimentoCientífico e Tecnológico (CNPq).

\section{Declaration of interest}

On behalf of all authors, the corresponding author states that there is no conflict of interest.

\section{References}

[1] Dalby J., Hayon R, Carlson J. Adolescent pregnancy and contraception. Prim Care 2014;41(3):607-29.

[2] Klein JD. Adolescent pregnancy: current trends and issues. Pediatrics 2005;116 (1):281-6.

[3] Baptista MN, Baptista ASD, Torres ECR. Associação entre suporte social, depressão e ansiedade em gestantes. Psic: revista da Vetor Editora 2006;7:3948.

[4] Freitas GV, Cais CF, Stefanello S, Botega NJ. Psychosocial conditions and suicidal behavior in pregnant teenagers : a case-control study in Brazil. Eur Child Adolesc Psychiatry 2008;17(6):336-42.

[5] Vesga-Lopez O, Blanco C, Keyes K, Olfson M, Grant BF, Hasin DS. Psychiatric disorders in pregnant and postpartum women in the United States. Arch Gen Psychiatry 2008;65(7):805-15.

[6] Dennis C-L, Falah-Hassani K, Shiri R. Prevalence of antenatal and postnatal anxiety: systematic review and meta-analysis. Br J Psychiatry 2018;210 (5):315-23.

[7] American Psychiatric Association. DSM-5: diagnostic and statistical manual of mental disorders. 5th ed Artmed Editora; 2014

[8] Sutter-Dallay AL, Giaconne-Marcesche V, Glatigny-Dallay E, Verdoux H. Women with anxiety disorders during pregnancy are at increased risk of intense postnatal depressive symptoms: a prospective survey of the MATQUID cohort. Eur Psychiatry 2004:19(8):459-63.

[9] Martini J, Knappe S, Beesdo-Baum K, Lieb R, Wittchen HU. Anxiety disorders before birth and self-perceived distress during pregnancy: associations with maternal depression and obstetric, neonatal and early childhood outcomes. Early Hum Dev 2010;86(5):305-10.

[10] Farias DR, de J Pinto T, Teofilo MM, Vilela AA, Vaz Jdos S, Nardi AE, et al. Prevalence of psychiatric disorders in the first trimester of pregnancy and factors associated with current suicide risk. Psychiatry Res 2013;210(3):962-8.

[11] Kingston D, Tough S, Whitfield H. Prenatal and Postpartum Maternal Psychological Distress and Infant Development: A Systematic Review. Child Psychiatry Hum Dev 2012;43(5):683-714.

[12] Faisal-Cury A, Menezes P, Araya R, Zugaib M. Common mental disorders during pregnancy: prevalence and associated factors among low-income women in São Paulo, Brazil. Arch Womens Ment Health 2009;12(5):335-43.

[13] Buist A, Gotman N, Yonkers KA. Generalized anxiety disorder: course and risk factors in pregnancy. J Affect Disord 2011;131(1):277-83.

[14] Ross LE, McLean LM. Anxiety disorders during pregnancy and the postpartum period: a systematic review. J Clin Psychiatry 2006;67(8):1285-98.

[15] Mitsuhiro SS, Chalem E, Barros MM, Guinsburg R, Laranjeira R. Teenage pregnancy: use of drugs in the third trimester and prevalence of psychiatric disorders. Rev Bras Psiquiatr 2006;28:122-5.

[16] Ma X, Xiang YT, Cai ZJ, Lu JY, Li SR, Xiang YO et al. Generalized anxiety disorder in China: prevalence, sociodemographic correlates, comorbidity, and suicide attempts. Perspect Psychiatr Care 2009;45(2):119-27.

[17] Pigott TA. Gender differences in the epidemiology and treatment of anxiety disorders. J Clin Psychiatry 1999;60(Suppl 18):4-15.

[18] Heider D, Matschinger H, Bernert S, Alonso J, Brugha TS, Bruffaerts R, et al. Adverse parenting as a risk factor in the occurrence of anxiety disorders: a study in six European countries. Soc Psychiatry Psychiatr Epidemiol 2008;43 (4):266-72.

[19] Coelho FM, Pinheiro RT, Silva RA, de Avila Quevedo L, de Mattos Souza LD, de Matos MB, et al. Parental bonding and suicidality in pregnant teenagers: a population-based study in southern Brazil. Soc Psychiatry Psychiatr Epidemiol 2014;49(8):1241-8.

[20] León CA, León A. Panic disorder and parental bonding. Psychiatr Ann 1990;20 (9):503-8.

[21] Epi-Info. A word processing database, and statistics program for epidemiology on microcomputers. Atlanta, USA: Center of disease control and prevention; 1994.

[22] Sheehan DV, Lecrubier Y, Sheehan KH, Amorim P, Janavs J, Weiller E, et al. The Mini-International Neuropsychiatric Interview (M.I.N.I.): the development and validation of a structured diagnostic psychiatric interview for DSM-IV and ICD-10. J Clin Psychiatry 1998;59(Suppl 20)22-33 quiz 4-57.

[23] Amorim P. Mini International Neuropsychiatric Interview (MINI): validação de entrevista breve para diagnóstico de transtornos mentais. Rev Bras Psiquiatr 2000;22:106-15.

[24] Terra L, Hauck S, Fillipon AP, Sanchez P, Hirakata V, Schestatsky S, et al. Confirmatory factor analysis of the parental bonding instrument in a brazilian female population. Aust N Z J Psychiatry 2009;43(4):348-54. 
[25] Hauck S, Schestatsky S, Terra L, Knijnik L, Sanchez P, Ceitlin LHF. Cross-cultural adaptation of parental bonding instrument (PBI) to brazilian portuguese. Revista de Psiquiatria do Rio Grande do Sul. 2006;28:162-8.

[26] Teodoro MLM, SPdC Benetti, Schwartz CB, Mônego BG. Psychometrics properties of Parental Bonding Instrument and association with family functioning. Avaliação Psicológica. 2010;9:243-51.

[27] Associação Brasileira de Empresas de Pesquisa. Dados com base no Levantamento Sócio Econômico (IBOPE). 2012.

[28] Victora CG, Huttly SR, Fuchs SC, Olinto MT. The role of conceptual frameworks in epidemiological analysis: a hierarchical approach. Int J Epidemiol 1997;26 (1):224-7.

[29] Lima AR, Mello MF, Mari Jd J. The role of early parental bonding in the development of psychiatric symptoms in adulthood. Curr Opin Psychiatry 2010;23(4):383-7.

[30] Rubinchik SM, Kablinger AS, Gardner JS. Medications for Panic Disorder and Generalized Anxiety Disorder During Pregnancy. Prim Care Companion J Clin Psychiatry 2005;7(3):100-5.

[31] Main M, Kaplan N, Cassidy J. Security in infancy, childhood, and adulthood: a move to the level of representation. Monogr Soc Res Child Dev 1985;50(1/ 2):66-104.
[32] Fentz HN, Arendt M, O'Toole MS, Rosenberg NK, Hougaard E. The role of depression in perceived parenting style among patients with anxiety disorders. J Anxiety Disord 2011;25(8):1095-101.

[33] Coleman PK. Abortion and mental health: quantitative synthesis and analysis of research published 1995-2009. Br J Psychiatry 2011;199(3):180-6.

[34] Beesdo K, Pine DS, Lieb R, Wittchen HU. Incidence and risk patterns of anxiety and depressive disorders and categorization of generalized anxiety disorder Arch Gen Psychiatry 2010;67(1):47-57.

[35] Lieb R, Isensee B, Hofler M, Pfister H, Wittchen HU. Parental major depression and the risk of depression and other mental disorders in offspring: a prospective-longitudinal community study. Arch Gen Psychiatry 2002;59 (4):365-74.

[36] Kessler RC, Wang PS. The descriptive epidemiology of commonly occurring mental disorders in the United States. Annu Rev Public Health 2008;29:11529.

[37] Murphy E, Wickramaratne P, Weissman M. The stability of parental bonding reports: a 20-year follow-up. J Affect Disord 2010;125(1-3):307-15. 